
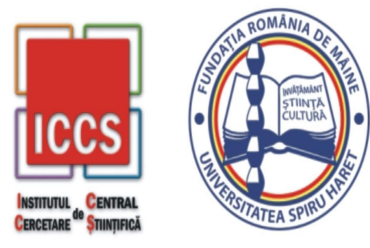

Issue 2/2019

\title{
HEALTH, A STRATEGIC NATIONAL RESOURCE
}

\author{
Alexandru Mihai ȘTEFĂNESCU ${ }^{1}$, Larisa MIHOREANU ${ }^{2}$, \\ Alexandra Rodica STEFĂNESCU ${ }^{3}$ \\ ${ }^{1}$ The Bucharest University of Economic Studies, 6 Piata Romana, 1st \\ district, Bucharest, 010374, Romania, Email: \\ dr.alexstefanescu@gmail.com \\ ${ }^{2}$ The Bucharest University of Economic Studies, 6 Piata Romana, 1st \\ district, Bucharest, 010374, Romania,Email: dr.mihoreanu@gmail.com \\ ${ }^{3}$ ANIMA Clinic Bucharest, Buzesti Street, no.75-77, $1^{\text {st }}$ District, \\ Bucharest, Email: astefanescu35@yahoo.com
}

How to cite: ȘTEFĂNESCU, A. M., MIHOREANU, L. \& ȘTEFĂNESCU, A. R. (2019). "Health, a Strategic National Resource." Annals of Spiru Haret University. Economic Series, 19(2), 115-123, doi: https://doi.org/10.26458/1925

\begin{abstract}
Health has always been the most valuable and beautiful gift that Nature offered to humans. Unfortunately, nowadays, people value and desire more wealth than health; often they remain indifferent to the degradation of their own health. Only in front of serious diagnoses people start appreciating their true wealth - the health. The allopathic medicine has no giants' power, as it sometimes treats symptoms and diseases instead of illnesses' fundamental causes.

Education, the other field revealing the horizon of knowledge, provides creative alternatives for spending revenues in favour of healthy individuals and societal robust development. The purpose almost remains the same: use both complex potentials and opportunities to increase motivation, accomplish joy of life and fulfil desires to build wellbeing. The link between Health and Education has complex links and hidden mechanisms waiting for to be explored and used in favour of all.
\end{abstract}

Keywords: health; indicators; resources; strategy. 


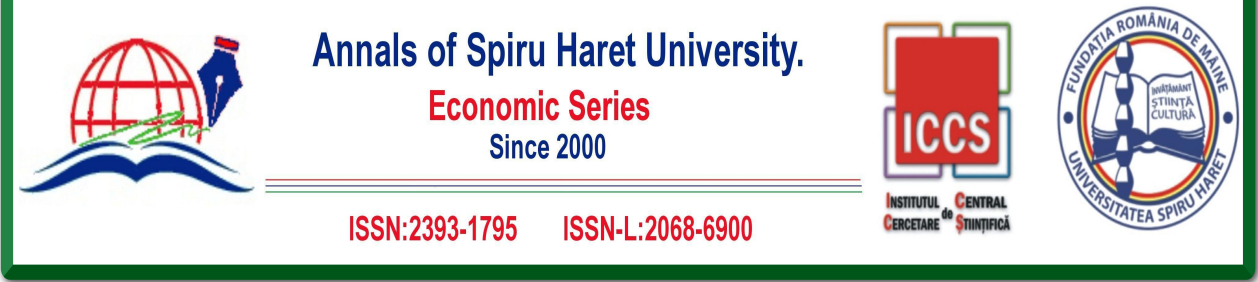

Issue 2/2019

JEL Classification: I10, I11, I15, I18

\section{Introduction}

As a given resource, health is not always correctly and fully respected, recognized and appreciated. Adapting to our society's reality dominated by a sedentary and stressful life, under the use of modern technologies, the disregard of the beneficial ancient customs leads to health early loss which disadvantages both individuals and society. A generalised feeling of passivity and major lack of interest in the society's life feed individuals suffering serious deprivations of wellbeing, deepen the roots of frustration, unhappiness, in favour of fake news and scandal ratings that people prefer to valuable knowledge and correct news. This general negative attitude becomes at present a national security issue, from a socio-economic, societaldemographic point of view for any nation. Although the technological-scientific momentum is constantly generating substantial discoveries in the medical field, the conscious spread of knowledge has a very low impact in the population. It is paradoxical that, despite all the scientific progress, knowledge about health is surprisingly low. How many of us know that $50 \%$ of myocardial infarction is not reported by any prior symptoms? How many of the young mothers are today aware that their own life styles - eating habits, consumption of cigarettes, coffee or alcohol - influence their health and determine the future of their children? Cases where children are born with chronic illnesses, with cardiac malformations, or with other rare conditions, appear and develop at a dramatic speed, because organisms are adapting bivectorally to the reality of the socio-environmental environment. Life is often shortened by conditions developed by negligent diets. Humanity reached the $21^{\text {st }}$ century without applying good practices to well nourish it. More and more cases of obesity occur particularly among children and adolescents who prefer junk-food instead of healthy fruits and vegetables. Few people know that obesity could lead to: abdominal hernia, varicose veins, flat foot, bronchitis, hypertension, diabetes, hypercholesterolemia, heart disease. Most chronic diseases are caused by today's lifestyle characterised by: too much food, drink, smoking and too little physical activity.

Although mental, social and spiritual factors are well-known to play an important role in our health, modern medicine neglects for various reasons these issues, and the effects of this process reflect globally, both socially and economically, on constantly 116 


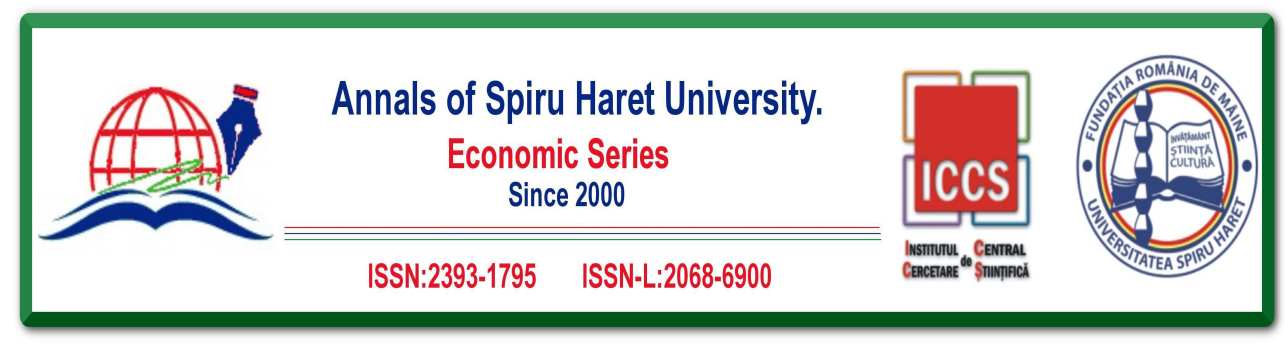

Issue 2/2019

higher costs, and causing impairments in the health sector's sustainability and generalized dysfunctions impacting on individuals life [Clark, 1997, Crespo et al., 1996].

The families incomes' rise is not only achieved by higher wages, but also by identifying and applying savings to different categories of expenditure: current medication (chronic and elderly patients), maintenance of unhealthy habits (alcohol, tobacco, other recreational drugs), unhealthy diet [Ford et al., 2009], spending on the use of means of transport (car, public transport over short distances) generating sedentary life styles - gasoilne, car maintenance costs [Crespo et al., 1996]. Such losses [Cox et al., 1987] are in parallel reflected at various levels: a) in the family budget [Ford et al., 2009] - where more money can be used for education, b) in the corporate budget - when firms can increase the employees' interest in other types of advantages or c) in the national budget - where the reduction of amounts allocated for treatments generated by unhealthy habits could be directed to increasing budgets for research, health prevention, medical education, rare diseases treatment [Watson et al., 2013]. Thus, as a result of the enlargement of the educational horizon and the accentuation of the implementation of creative alternatives, additional sources of non-spent money or of income saved by intelligent management can be used for high quality entertainment [de Groot et al., 2004], development of physical and mental potential derived from the desire to live a full life [Tarlov, 1998], accomplish the need to contribute to community - with family, friends, high quality company, etc.

The administrative and economic-organizational consequences [Tarlov, 1998] will get differently pictured: - creating the image of the true value of the outpatient treatment process; • reducing the hospitalization in medical establishments; • strengthening the care function by allocating more precisely the resources for medical care, education, nutrition; - referral of medical evaluation and monitoring firstly to family medicine and primary care; $\bullet$ orientation of the medical system to other coordinates of true diagnosis, investigation and treatment [Pakholok, 2013]. Cultivating health education needs a change of lifestyle, and this factor has medical, social, economic and institutional-societal implications that require detailed clarifications [WHO, 2013].

The concept of health is available in all policies and strategies of complementary horizontal policies that contribute to improving the population health. Examining the health determinants and factors influencing the health development, it is quite obvious that they are mainly controlled by other sectoral policies than health; the 

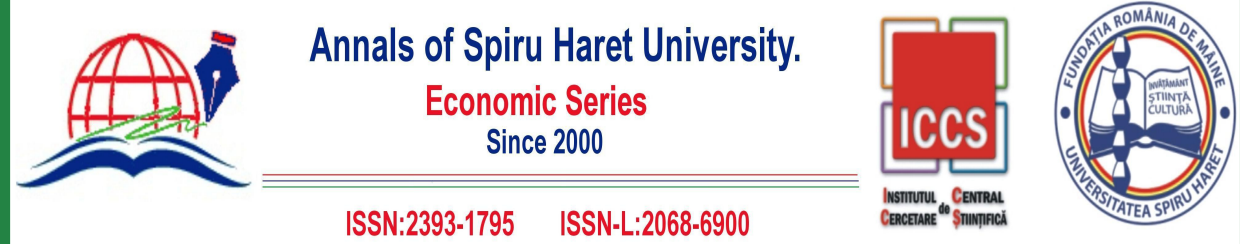

Issue 2/2019

political actions, defined as coordinated actions, explicitly target the people's health improvement [Pascu-Gabără \& Mihoreanu, 2019]. Intersectoral actions for health are considered essential for achieving equity in the sector, especially if progress relies on robust decisions and other sectors' actions. The term intersectoral was originally used with reference to the collaboration between various public sectors; it was later used for collaboration between the public and the private sector. It can also be used to outline the vectorial direction of sound decisions, actions, achievements, under a proactive and robust partnering [Pascu-Gabără \& Mihoreanu, 2019].

\section{Health - Mirage, Art, Science}

Prior to be considered a science, health represents the mirage of life. We can touch it but we can never contain it entirely. Here it is the temptation to use multicriteria to define the health and to measure it according to other referring norms, standards, barometers. In the very broad list of health definitions, several criteria are used, depending on the school of thoughts: functional well-being, the body's ability to adapt to the various conditions of life and work, the human condition that makes the individual creative. According to WHO (2013), health reflects a "state of harmony and well-general and complete, physically, mentally and socially, which does not only mean the absence of disease or infirmity". The features of this definition are: it is generally accepted as an "aspiration"; its achievement implies the entire societal responsibility; it underlines its positive sides and multi-axial nature of health. The health of human groups can be defined as a synthesis of individual's health appreciated in a synthetic, global eco-systemic vision. When they are healthy, people do not value their health, but when it deteriorates, it is found to be lacking. In other words, to appreciate it, we must lose it. Just like freedom.

The health determinants [Crespo, 1996] refer to factors proven to influence the health in any way: the social, economic and physical environment, the particular characteristics of individuals and patients' behaviours. The social and economic conditions - such as poverty, social exclusion and unemployment - have also a strong impact on health. All these factors play a part in health inequalities making the link between people living in poverty who die earlier and get sicker than people living in good living conditions.

Socially privileged health factors represent better social conditions of life and work. These determinants indicate the "specific characteristics" issuing from particular, 


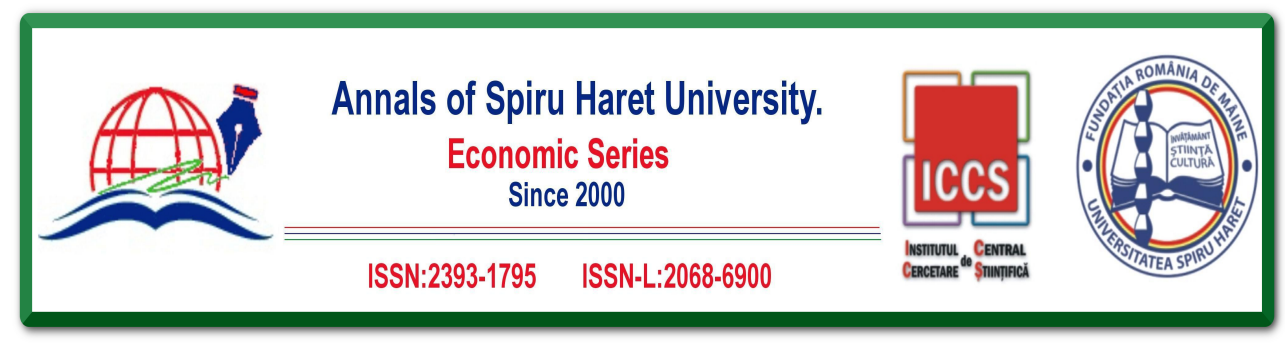

Issue 2/2019

national and societal environments that affect health and the ways in which "social conditions translate into impact on health" [Paşcu-Gabără \& Mihoreanu, 2019].

Health promotion envisages health as a resource for everyday life [Ford, 2009]. The concept positively calls attention to aggregated resources (individual and social) focusing also on the physical capabilities.

Promoting health embodies the operational process to capacitate both individuals and communities increasing their control over the determinants of health as a major approach to improve their own health status. This embodies a plan of action in the field of mental, physical and social health perceived as both a political strategy and an approach that makes possible to straighten the general lifestyle for the benefit of health. The health logistics is greater than we usually imagine: near includes ministries, departments, clinics and sections, other important bodies have to be considered: safety social security systems, volunteer organizations, non-governmental entities, support and palliative groups and individuals (patients, family, affiliated contributors). Each item is important for the health wheel to rule correctly.

\section{Health - European or National Strategic Goal}

Health - is both a national and an European strategic goal, given the fact that Romania is now a member of the European Union. Since 2007, the national legislation on health and safety at work has been harmonized with the European one, with major legislative improvements and good results. The European Union's strategy for occupational health and safety aims at: covering maximum risks with minimum of directives in order to avoid fragmentation of the legislation; meeting the specific requirements of certain high-risk activities or sectors, as well as certain categories of vulnerable workers; ensuring consistency between Community provisions with a view to the completion of the internal market defining the essential health and safety requirements to be observed at the design, manufacturing and marketing stage of products and the provisions of the directives adopted relating to the use of products at work. The strategic objectives of the new European Union strategy on health and safety at work are: - the overall approach to workplace wellbeing by taking into account changes in the work environments and emerging new risks and managerial non-conformities, being aimed at increasing work quality, reducing work-related accidents and preventing occupational diseases; • taking into account the demographic changes in terms of risks, changes in (non)contractual employment arrangements, work organization, working place and working time; 


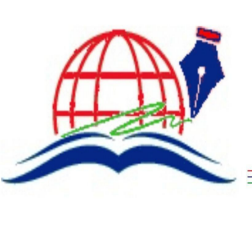

Annals of Spiru Haret University.

Economic Series

Since 2000
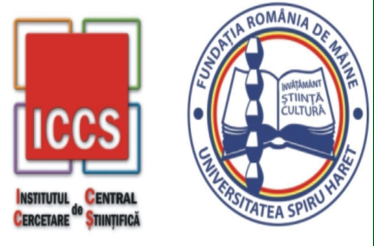

\section{Issue 2/2019}

analysis of new risks; - strengthening a culture of risk prevention by combining a variety of political tools and legal instruments like mediation, social dialogue, measures and good practices, social responsibility and economic incentives based on building partnerships between stakeholders involved in work safety and health: education, risk-awareness, anticipation, more effective enforcement of existing legislation; - existence of an adequate social policy as a factor in the competitiveness equation, knowing that "non-policy" ever generates risks.

Like all European countries, Romania achieved significant gains in the field of health; however, it still has more to change appears both in the national and European agendas for the coming years. The biggest issue concerns the ways in which the tasks are assigned, what are the local expectations and how all actors involved in different activities can improve their skills and attitude to sustain the change, innovation and sustainability, how the harmonization of facts and acts can happen for the general benefit. Unfortunately, when the primary health sector is underdeveloped, the health services are mostly provided by the hospitals, at higher costs, using more resources, spending more time and energy compared to developed countries. When community services are almost invisible, ambulatory care is provided by the hospitals too, instead of enlarging the general practitioners' portfolio, create and develop the clinics of proximity, environment based on outsourced specialized services.
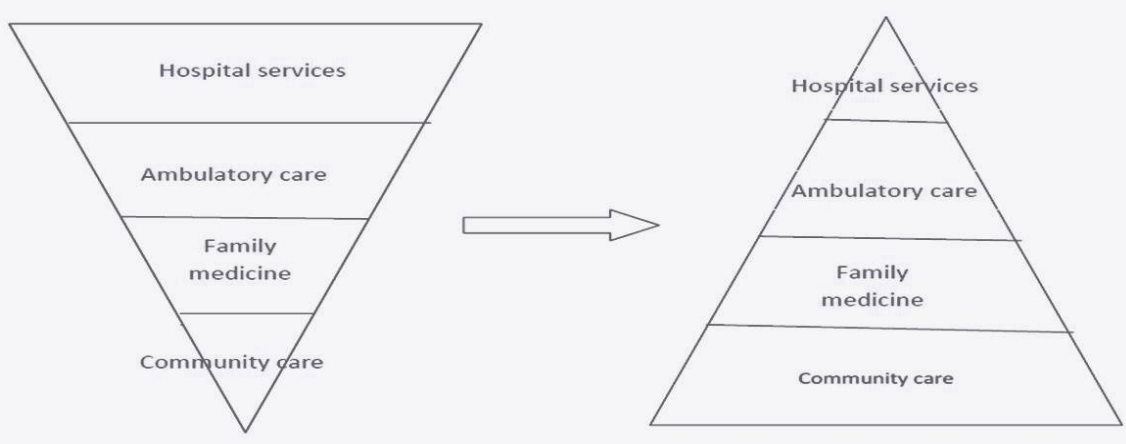

Fig. 1. 2014/2020 Health Services Consumption Pyramid Comparison between 2014 (Left) and 2020 (Right) - personal approach 


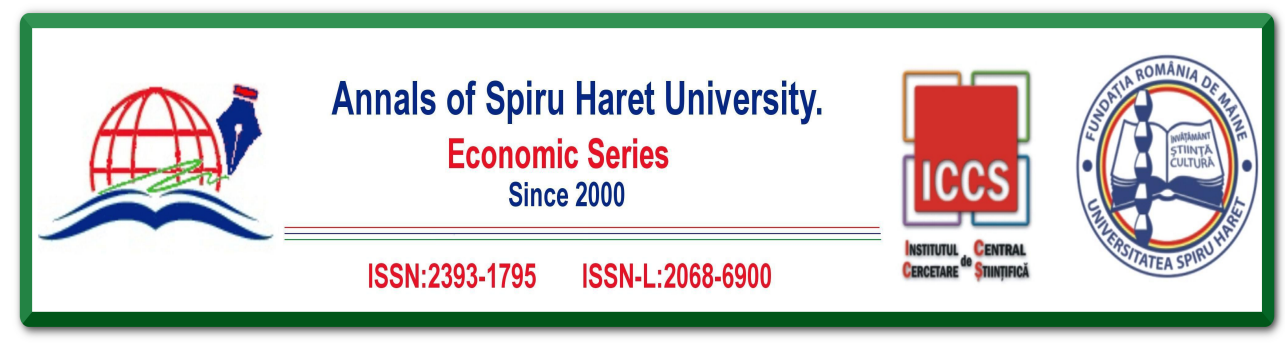

Issue 2/2019

The new Health 2020 concept is based on the values enshrined in the WHO Constitution, which seeks to ensure "the highest standard of health" as the fundamental right of the modern man. As European social states are restructured, the need for constant vigilance and the active promotion of a policy of true values based on civil rights and attitudes will persist. The idea of assessing the state of health in Romania and identifying ways to re-establish the health policies is an integral part of a strategic political goal outlining the fact that health as a physical status is precious but as an economic sector is pricy. In this context, the purpose of such research will ultimately meet better indicators reflecting the medical budget limits and constraints and the Romanian society reality as it is perceived and lived by patients and specialists.

The National Health Strategy represents the commitment of health decision makers from the public sector to ensure and promote health as a key determinant of a sustainable development of Romanian society, from the social, territorial and economic point of view, as the engine of progress and prosperity of the nation. It provides the overall framework for intervention to eliminate the identified weaknesses in the health sector by: reducing important health inequalities, optimizing the use of resources in health services in increased cost-effectiveness with evidence-based medicine and, last but not least, to improve administrative capacity and management quality at all levels.

Romania has the obligation to harmonise the national legislation in the field of health and safety at work; this process started in 2007 and is not yet completed. The new law of health in force provides new dimensions for the healthcare development - through operational integration with the other sectors outlining the prevention and promotion as cross-sectoral collaborative tools between governmental authorities, non-governmental organizations, community entities and the private sector. Despite the measures implemented, the situation in the Romanian clinics and hospitals is still unchanged because of lacks in logistical modernization, old attitude towards community, patients and the other specialists, lack of responsible engagement and awareness in accounting efforts, losses, best practices, the lack of assumed commitment and proactive role for the general well-being implementation and systemic ankylosis elimination. No matter how rich a country could be, without the proactive contribution of the citizens, wellness and health can't be implemented. In the process of learning something new, people should learn that the general knowledge is wider than ours; to know more, we must accept the value of the general knowledge and the importance of the collective effort. To get the best we need firstly 


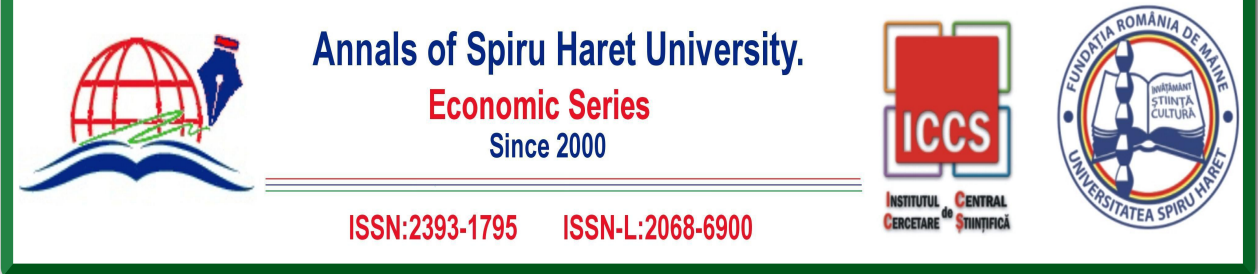

\section{Issue $2 / 2019$}

to understand what we need and what we can acquire by our own efforts and appreciating the general achievements. Prior to build a healthier society, we have to accept who we are, and what are the classical mistakes we do, how we can develop and carefully use our society limited resources. If we understand that lesson, we will be able to move on towards the sound health.

\section{References}

[1] Clark, Florence; Stanley P. Azen; Ruth Zemke; Jeanne Jackson; Mike Carlson; Deborah Mandel; Joel Hay; Karen Josephson; Barbara Cherry; Colin Hessel; Joycelynne Palmer and Loren Lipson. (1997). "MD Occupational Therapy for Independent-Living Older Adults A Randomized Controlled Trial." The Journal of the American Medical Association, Vol. 278(16), pp. 1321-1326.

[2] Contoyannisa, Paul and Andrew M. Jonesb. (2004). "Socio-economic status, health and lifestyle." Journal of Health Economics, Vol. 23, Issue 5, Sept., pp. 965-995.

[3] Cox, B.D.; Blaxter, M.; Buckle, A.L.J.; Fenner, N.P.; Golding, J.F.; Gore, M.; Huppert, F.A.; Nickson, J.; Roth, Sir M.; Stark, J.; Wadsworth, M.E.J. and Whichelow, M. (1987). The health and lifestyle survey. Preliminary report of a nationwide survey of the physical and mental health, attitudes and lifestyle of a random sample of 9,003 British Adults. 212 pp. ISBN0-9512272-0-3.

[4] Crespo, Carlos J.; Steven J. Keteyian; Gregory W. Heath and Christopher T. Sempos. (1996). "Leisure-Time Physical Activity Among US Adults Results From the Third National Health and Nutrition Examination Survey." Arch Intern Med., Vol. 156(1), pp. 93-98.

[5] de Groot Lisette C.P.M.G., Marieke W. Verheijden, Stefaan de Henauw, Marianne Schroll and Wija A. van Staveren. (2004). "Lifestyle, Nutritional Status, Health, and Mortality in Elderly People Across Europe: A Review of the Longitudinal Results of the SENECA Study Oxford Journals Medicine." The Journals of Gerontology: Series A Vol. 59, Issue 12, pp. 1277-1284.

[6] Ford, Earl S.; Manuela M. Bergmann; Janine Kröger; Anja Schienkiewitz; Cornelia Weikert and Heiner Boeing. (2009). "Healthy Living Is the Best Revenge: Findings From the European Prospective Investigation Into Cancer and Nutrition-Potsdam Study." Arch Intern Med.; Vol. 169(15), pp. 1355-1362.

[7] Pakholok, Olga. (2013). The Idea of Healthy Lifestyle and its transformation Into Health-Oriented Lifestyle in Contemporary Society, DOI: 10.1177/2158244013500281 SAGE Open 


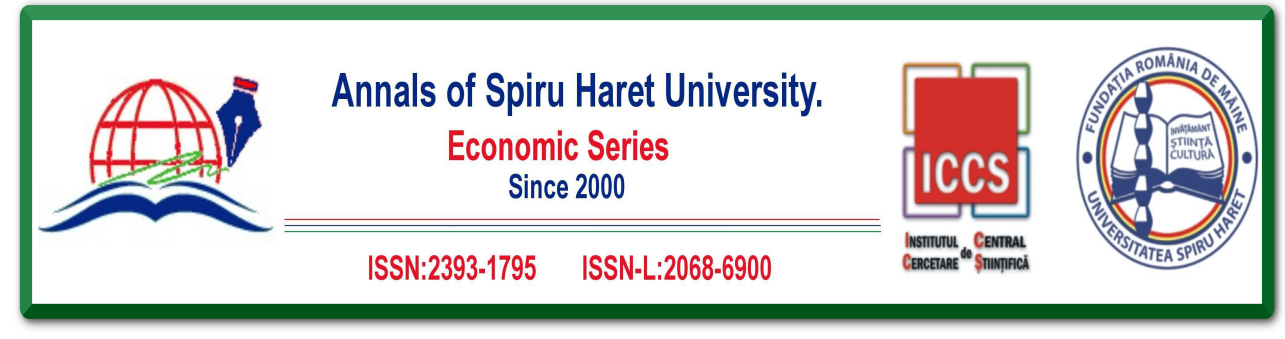

Issue 2/2019

[8] Paşcu-Gabără Elena-Iuliana and Larisa Mihoreanu. (2019). "A Triple Layer Model to Manage Romania's Health Risks and Educational Consequences.” Journal of Economic Development, Environment and People, Vol. 8, Issue 1, URL: http://jedep.spiruharet.ro

[9] Tarlov, Alvin R.; John E. Ware Jr; Sheldon Greenfield; Eugene C. Nelson; Edward Perrin and Michael Zubkoff. (1998). "The Medical Outcomes Study An Application of Methods for Monitoring the Results of Medical Care." The Journal of the American Medical Association, Vol. 262 (7), pp. 925-930.

[10] Watson, Lea C., Joanne M. Garrett, Philip D. Sloane, Ann L. Gruber-Baldini and Sheryl Zimmerman. (2013). "Depression in Assisted Living: Results From a Four-State Study." The American Journal of Geriatric Psychiatry, Vol. 11, Issue 5, Sept.-Oct., pp. 534-542.

[11] World Health Organization. (2013). Research for universal health coverage: World Health Report, ISBN: 9789241564595. 
